TITLE:

\title{
Attending inside or outside: A Japanese-US comparison of spontaneous memory of group information
}

\section{$\operatorname{AUTHOR}(\mathrm{S})$ :}

Takemura, Kosuke; Yuki, Masaki; Ohtsubo, Yohsuke

\section{CITATION:}

Takemura, Kosuke ... [et al]. Attending inside or outside: A Japanese-US comparison of spontaneous memory of group information. Asian Journal of Social Psychology 2010, 13(4): 303-307

\section{ISSUE DATE:}

2010-12

URL:

http://hdl.handle.net/2433/131756

\section{RIGHT:}

(c) 2010 The Authors. Asian Journal of Social Psychology (c) 2010 Blackwell Publishing Asia Pty Ltd with the Asian Association of Social Psychology and the Japanese Group Dynamics Association; 許諾条件により本文は2011-12-01に 公開; This is not the published version. Please cite only the published version.; この論文は出版社版でありません。引用 の際には出版社版をご確認ご利用ください。 
Asian Journal of Social Psychology (2010), 13, 303-307

RUNNING HEAD: Culture and Groups

Attending inside or outside:

\title{
A Japanese-US comparison of spontaneous memory of group information
}

\author{
Kosuke Takemura \\ University of British Columbia
}

Masaki Yuki

Hokkaido University

and

Yohsuke Ohtsubo

Kobe University

Keywords: attention, cross-cultural difference, group process, memory

Correspondence: Kosuke Takemura, Department of Psychology, University of British Columbia, 2136 West Mall, Vancouver, BC V6T 1Z4, Canada. Email: boz.takemura@gmail.com 


\begin{abstract}
A recent review of empirical evidence disconfirmed the widely-held view that North Americans are less collectivistic than East Asians. However, previous research has proposed that the motivations underlying group behaviours differ across cultures: North Americans are more strongly motivated to acquire and maintain higher in-group status relative to outgroups, whereas East Asians tend to emphasize maintenance of reciprocal relationships within in-groups. We tested this hypothesis by examining the pattern of attentional allocation in group situations using a memory task. As predicted, compared to Japanese, memory performance among Americans was biased towards intergroup status difference over intragroup relationship information.
\end{abstract}


Following the seminal study by Hofstede (1980), an abundance of research has been conducted on cross-cultural differences in individualism/collectivism as a basic dimension of cultural norms and values across the globe (for reviews, see Oyserman, Coon, \& Kemmelmeier, 2002; Triandis, 1995). In brief, individualistic cultures are characterized by an emphasis on autonomy and differentiation of the individual self from others, an orientation that places priority on personal goals, rather than the goals of collectives. Collectivistic societies, conversely, are characterized by social embeddedness and interdependence with significant others and groups, with an emphasis on collective goals, rather than personal goals (Oyserman et al., 2002; Triandis, 1989).

Although it is widely believed that North Americans are highly individualistic and less collectivistic compared with people in other parts of the world, such as East Asian (e.g. Hofstede, 1980; Triandis, 1995), accumulating empirical evidence has revealed a more complex story. In a meta-analysis of results of 83 studies of individualism and collectivism across a variety of cultures, Oyserman et al. (2002) found that Americans generally score high on measures of individualism, but these researchers also found that Americans are actually as collectivistic as Koreans, and even more collectivistic than Japanese on several measures of values and attitudes. Additionally, several cross-cultural studies have revealed a strong group-oriented tendency among North Americans. For instance, compared to people in other parts of the world, North Americans show stronger in-group bias in in-group and outgroup evaluations (Heine \& Lehman, 1997; Rose, 1985; Snibbe, Kitayama, Markus, \& Suzuki, 2003), in trust (Yuki, Maddux, Brewer, \& Takemura, 2005), and in reward allocation (Buchan, Croson, \& Johnson, 2003). 
Although it has been shown that both East Asians and North Americans are strongly group oriented, Yuki (2003) argued that the underlying motivations causing these similar group orientations might nonetheless differ. In particular, East Asians might be more oriented towards 'intragroup relationships'. The in-group for East Asians might be cognitively represented as a relatively stable and structured network of relationships among group members, and people might be motivated to maintain harmonious/reciprocal relationships among in-group members. Their primary self-concept is a more relational self (Brewer \& Gardner, 1996; Kashima \& Hardie, 2000; Markus \& Kitayama, 1991); they might chronically perceive themselves to be personalized from, but connected with, other in-group members, and they are aware of the exact location of the self within the interpersonal network. In other words, East Asians tend to perceive the self as a 'node' embedded within the network among in-group members.

In contrast, North Americans might be more oriented towards 'intergroup comparisons'. They tend to think about social groups as categories of depersonalized members, and define themselves based on the prototypicality of their in-groups (i.e. collective self; Brewer \& Gardner, 1996). In-group-outgroup differentiation is made primarily based on categorical distinctions, rather than presence versus absence of interpersonal connectedness (Yuki et al., 2005). People are motivated to gain and maintain positive intergroup distinctiveness. Such a conceptualization of group processes is consistent with ones presumed by the social identity theory (Tajfel $\&$ Turner, 1979) and the related self-categorization theory (Turner, Hogg, Oakes, Reicher, \& Wetherell, 1987).

Although the cross-cultural study by Yuki (2003) yielded results consistent 
with the hypothesis that the motivations underlying a strong group orientation differ between East Asians and North Americans, this study's conclusions are weakened by a reliance on subjective Likert scales. Likert scales are easy to administer, and therefore, a useful tool for efficiently collecting data across cultures. However, there are several problems with making cross-cultural comparisons using Likert scales. For instance, different cultures might have different response sets (e.g. Bond, 1988; Chen, Lee, \& Stevenson, 1995; Leung \& Bond, 1989) or might use different reference groups when making judgments (Heine, Buchtel, \& Norenzayan, 2008; Heine, Lehman, Peng, \& Greenholtz, 2002; Takemura, Yuki, Kashima, \& Halloran, 2007). It is therefore crucial to examine the hypothesized cultural differences through other methods. One potential method is to assess people's 'online' responses or mental responses that are produced spontaneously as people behave in actual social settings (Kitayama, 2002).

As an indicator of online response, we chose to assess North Americans' and East Asians' spontaneous attention to: (i) intergroup status differences; and (ii) intragroup relationships. We conducted an experiment using a surprise memory task in the USA and Japan. Participants were asked to read three scenarios that described typical situations in people's daily lives, each of which included information about the relationships between hypothetical in-groups and outgroups, as well as about the relationships between members within the in-group. After reading all scenarios, participants' recognition memory for the two types of information was tested. By assessing attention with a memory task, the current study is free from the potential confound as a result of cultural differences in use and interpretation of self-report scales. Also, since a memory task does not require self-reflective reports, the results obtained by the current study are not affected by the reference group effect, which is produced 
through social comparison processes (Festinger, 1954). It was predicted that memory performance among US participants would be, when compared to that of Japanese participants, biased towards intergroup status difference information over intragroup relationship information.

\section{Method}

Seventy-seven (54 female and 23 male) students at Nara University, Nara, Japan, and 36 (20 female and 16 male) students at Northwestern University, Chicago, Illinois, USA participated in the experiment. Japanese participants were recruited from the local participant pool via email and volunteered to participate in the study in exchange for a monetary payment of $¥ 1000$ (approximately \$US 10). Participants in the USA signed up for the experiment on a website maintained by the university for research purposes, and participated for \$US 10. The average ages of the participants were 18.7 and 19.9 years for the Japanese and US samples, respectively.

The experiment was introduced as a study about impression formation. Participants were asked to read three scenarios for 3 min each. Each scenario depicted a situation involving three groups, one of which was described as the participants' in-group. One of three scenarios was about three corporations located in the same building (corporation scenario), another was about three student clubs in the same university (club scenario), and the third was about three universities in the same area (university scenario). Every scenario included several pieces of information regarding status differences between the three groups (intergroup comparison information), as well as relationships between three in-group members and their cooperativeness (intragroup relationship information). For example, in the club scenario, participants 
read about their in-group, a karate club, and two other clubs (debate and drama clubs) in the same university. Part of the scenario read that the karate club and the debate club were very highly regarded, while the drama club was not (i.e. intergroup comparison information). Other parts of the scenario described intragroup relationships; for example, Lisa likes Barbara, Barbara dislikes James, James follows the club's rules, Barbara is dedicated to instructing new members. After each scenario, participants were asked to work for 2 min on a filler questionnaire consisting of six items measuring their impressions of the in-group and its members. The order of the scenarios was counterbalanced across participants. The order of information exposure within each scenario was also counterbalanced. Half of the participants received questionnaires in which all scenarios began with the intergroup comparison information; the other half received questionnaires in which all scenarios began with the intragroup relationship information. During this phase of the experiment, no mention was made of the memory test that would follow.

After completing the last filler questionnaire, participants then completed the surprise memory test. For each scenario, participants responded to six questions about intergroup comparison information, and 12 questions about intragroup relationship information were presented. ${ }^{1}$ Each question was multiple choice with three alternatives. A sample item for intergroup comparison information was: 'Which club is regarded more positively at the university?' (options: 'the drama club', 'the karate club', and 'about the same'). Sample items for intragroup relationship information were: 'Who participates in club activities more frequently?' (options: 'James Davis', 'Barbara Miller', and 'about the same') and 'How does Lisa Taylor feel about James Davis?' (options: 'negative', 'neutral', and 'positive'). There was no time limitation to complete 
this questionnaire. Finally, participants gave demographic information.

The scenarios and all questions were constructed simultaneously in English and Japanese. Equivalence was checked through a retranslation of the English version into Japanese by a bilingual who did not know of the original Japanese version.

\section{Results}

The dependent variables were rates of correct recognition for the intergroup comparison and intragroup relationship information. This was computed as the number of correctly recognized items divided by the total number of items (i.e. a total of six for the intergroup orientation score and 12 for the intragroup orientation score).

It should be noted that, in the analysis below, we focused on the interaction between culture and the type of information, not on the simple main effect of culture or information type. Interpretations based on the simple main effects are potentially misleading. First, the simple main effect of culture within each kind of information could be confounded with cultural differences in general memory ability. Even if the difference between the Japanese and US samples was detected in one type of information, this observed cultural difference might be caused by the fact that people from one culture have better memory ability than people from the other culture.

Interpreting the simple main effect of information type is also problematic. There might be differences in how difficult it is to remember the two types of information (this could arise, for instance, through unintentional differences in how we worded the types of information). Therefore, the simple main effect of information type might not reveal differences in attention, per se.

Instead, we examine cultural differences in the 'pattern' between two types of 
information. Statistically, this requires examining the interaction between culture and information type (see Aaker \& Lee, 2001; Hamamura, Meijer, Heine, Kamaya, \& Hori, 2009; Wagar \& Cohen, 2003 for similar approaches when interpreting the results of cross-cultural memory experiments).

Figure 1 shows the mean correct recognition rates as a function of culture and information type. We conducted a 2 (culture) x 2 (information type), mixed-model ANOVA, with the latter factor involving repeated measures, on the recognition rate. The results showed that the main effect for culture was not significant, as indicated by $F(1$, 111) $=0.19, p=0.660, \eta_{\mathrm{p}}{ }^{2}=0.002$, and the main effect for information type was marginally significant, as indicated by $F(1,111)=3.03, p=0.085, \eta_{\mathrm{p}}{ }^{2}=0.027$, with the recognition rate for intergroup comparison information marginally higher than the recognition rate for intragroup relationship information. However, this effect was qualified by the predicted interaction effect between culture and information type, as indicated by $F(1,111)=3.98, p=0.048, \eta_{\mathrm{p}}{ }^{2}=0.035$. $^{2}$ As can be seen in Figure 1 , the patterns of the recognition rates for two types of information differed by culture: the US sample showed a higher recognition rate for intergroup comparison information relative to the intragroup relationship information, whereas the Japanese sample did not differ in their recognition rate for the two types of information. ${ }^{3}$ That is, consistent with our expectation, compared to Japanese, memory performance among Americans was biased towards intergroup comparison information over intragroup relationship information.

\section{Discussion}

Accumulating cross-cultural evidence suggests that North Americans, who are traditionally characterized to be 'individualistic', are in fact no less collectivistic than 
East Asians (e.g. Buchan et al., 2003; Heine \& Lehman, 1997; Oyserman et al., 2002;

Snibbe et al., 2003). However, it has been proposed that group processes are qualitatively different across cultures. North Americans' group processes are more category based while East Asians' group processes are more relationship based (Brewer \& Yuki, 2007; Yuki, 2003). Although there is some existing literature that has directly tested this hypothesis (e.g. Yuki), its conclusions are weakened by a reliance on Likert scales (on problems with Likert scales, see Chen et al., 1995; Heine et al., 2002, 2008; Kitayama, 2002; Takemura et al., 2007). To address this problem, this study used another type of measure, memory performance for intergroup comparison and intragroup relationship information.

The results supported our predictions: when different kinds of information about fictitious social groups were presented in the same scenarios, memory performance among Americans was, when compared to that of Japanese, biased towards intergroup status difference information over intragroup relationship information. This is consistent with the hypothesis that North Americans are more intergroup comparison oriented, whereas East Asians are more intragroup relationship oriented.

Although the current research contributes to a growing literature on the multifaceted nature of collectivism, several issues remain unanswered. One of the limitations of the current study is the fact that the valence of the intergroup comparison information was not fully balanced. As previous studies have suggested, people tend to identify more strongly with high-status in-groups than low-status in-groups (e.g. Sachdev \& Bourhis, 1991). Therefore, in the current study, among the 18 sets of intergroup status difference information provided, seven indicated that the in-group had a higher status than outgroups, whereas only two stated that the in-group had a lower 
status (the other information was either neutral, i.e. in-group- and outgroup-status being equal, or information about relationships between outgroups). This was done in order to help participants identify themselves with their in-group. It should be noted that our post-hoc analyses indicated that the same memory pattern was observed for in-group high-status and in-group low status information; there was no significant interaction effect between culture and the information valence on memory performance $[F(2,222)$ $\left.=0.02, p=0.978, \eta_{\mathrm{p}}{ }^{2}<0.001\right]$. In any case, future studies should examine if the cultural differences that were found in this study will be observed when the valence of information is manipulated.

Another issue which should be addressed by future research is the relationship between intergroup comparison orientation and individualism. As mentioned earlier, a number of studies have confirmed that North Americans are highly individualistic. Simultaneously, however, they are also found to be highly group oriented (e.g. Buchan et al., 2003; Heine \& Lehman, 1997; Rose, 1985; Snibbe et al., 2003; Yuki et al., 2005; see also Oyserman et al., 2002 for a meta-analytic review). The current study contributes to identifying one of the features of North American group orientation: it is an orientation towards intergroup comparison. It will be an exciting task for future research to investigate why seemingly incongruous tendencies, individualism/independence, and intergroup comparisons coexist among North Americans.

Finally, the antecedent factors of the cultural differences that the present study found are also not known. The question of what factors cause cultural differences in intragroup relationship orientation and intergroup comparison orientation remains unanswered. The current hypothesis argues only about the differences between North 
American and East Asian societies; however, if we can identify ultimate factors that give rise to these cultural differences, it will become possible to predict differences even between societies outside of North America and East Asia. This line of research will deepen our understanding, not only about the diversity of human group behaviour and psychological processes underlying it, but also about the mechanisms which yield this diversity. 
Acknowledgements

This research was supported by a grant-in-aid for the Encouragement of Young Scientists (A), 16683002, from the Japan Society for the Promotion of Science, to Masaki Yuki. Kosuke Takemura was supported by the Canadian Post-Doctoral Research Fellowship Program. The authors would like to thank Dr. William W. Maddux at INSEAD (Fontainebleau, France) for his help throughout the study, Vanessa Hsieh (Northwestern University, Chicago, IL, USA), and Takamasa Sasaki (Hokkaido University, Sapporo, Hokkaido, Japan) for their help with data collection, and Benjamin Cheung (University of British Columbia, Vancouver, BC, Canada), Dr. David Dalsky (Kyoto University, Kyoto, Japan), Andrew W. Delton (University of California, Santa Barbara, CA, USA), Dr. Vinai Norasakkunkit (Minnesota State University, Mankato, MN, USA), and Joanna Schug (Hokkaido University, Sapporo, Hokkaido, Japan) for their helpful comments on earlier versions of this manuscript. 


\section{References}

Aaker, J.L., \& Lee, A.Y. (2001). "I" seek pleasures and "we" avoid pains: The role of self-regulatory focus goals in information processing and persuasion. Journal of Consumer Research, 28, 33-49.

Bond, M.H. (1988). Finding universal dimensions of individual variation in multicultural studies of values: The Rokeach and Chinese value surveys. Journal of Personality and Social Psychology, 55, 1009-1015.

Brewer, M.B., \& Gardner, W. (1996). Who is this “we"? Levels of collective identity and self representations. Journal of Personality and Social Psychology, 71, 83-93.

Brewer, M.B., \& Yuki, M. (2007). Culture and social identity. In S. Kitayama \& D. Cohen (Eds.), Handbook of cultural psychology (pp. 307-322). New York: Guilford Press.

Buchan, N.R., Croson, R., \& Johnson, E.J. (2003). Let's get personal: An international examination of the influence of communication, culture, and social distance on trust and trustworthiness. Working paper, University of Wisconsin, Madison.

Chen, C., Lee, S.-y., \& Stevenson, H.W. (1995). Response style and cross-cultural comparisons of rating scales among East Asian and North American students. Psychological Science, 6, 170-175.

Festinger, L. (1954). A theory of social comparison processes. Human Relations, 7, 117-140.

Hamamura, T., Meijer, Z., Heine, S.J., Kamaya, K., \& Hori, I. (2009). Approach-avoidance motivation and information processing: Cross-cultural analysis. Personality and Social Psychology Bulletin, 35, 454-462.

Heine, S.J., Buchtel, E., \& Norenzayan, A. (2008). What do cross-national comparisons 
of self-reported personality traits tell us? The case of conscientiousness. Psychological Science, 19, 309-313.

Heine, S.J., \& Lehman, D.R. (1997). The cultural construction of self-enhancement: An examination of group-serving biases. Journal of Personality and Social Psychology, 72, 1268-1283.

Heine, S.J., Lehman, D.R., Peng, K., \& Greenholtz, J. (2002). What's wrong with cross-cultural comparisons of subjective Likert scales? The reference-group effect. Journal of Personality and Social Psychology, 82, 903-918.

Hofstede, G. (1980). Culture's consequences: International differences in work-related values. Beverly Hills, CA: Sage.

Kashima, E.S., \& Hardie, E.A. (2000). The development and validation of the relational, individual, and collective self-aspects (RIC) scale. Asian Journal of Social Psychology, 3, 19-48.

Kitayama, S. (2002). Culture and basic psychological processes-Toward a system view of culture: Comment on Oyserman et al. (2002). Psychological Bulletin, 128, 89-96.

Leung, K. \& Bond, M.H. (1989). On the empirical identification of dimension for cross-cultural comparisons. Journal of Cross-Cultural Psychology, 20, 133-151.

Markus, H.R. \& Kitayama, S. (1991). Culture and the self: Implications for cognition, emotion, and motivation. Psychological Review, 98, 224-253.

Oyserman, D., Coon, H.M., \& Kemmelmeier, M. (2002). Rethinking individualism and collectivism: Evaluation of theoretical assumptions and meta-analyses. Psychological Bulletin, 128, 3-72.

Rose, R. (1985). National pride in cross-national perspective. International Social 
Science Journal, 103, 85-96.

Sachdev, I., \& Bourhis, R.Y. (1991). Power and status differentials in minority and majority group relations. European Journal of Social Psychology, 21, 1-24.

Snibbe, A.C., Kitayama, S., Markus, H.R., \& Suzuki, T. (2003). They saw a game: A Japanese and American (football) field study. Journal of Cross-Cultural Psychology, 34, 581-595.

Tajfel, H., \& Turner, J. (1979). An integrative theory of intergroup conflict. In W.G. Austin \& S. Worchel (Eds.), The social psychology of intergroup relations (pp. 33-47). Monterey, CA: Brooks/Cole.

Takemura, K., Yuki, M., Kashima, E.S., \& Halloran, M. (2007). A cross-cultural comparison of behaviors and independent/interdependent self-views. In A.B.I. Bernardo, M.C. Gastardo-Conaco, \& M.E.C.D. Liwag (Eds.), The self, relationships, and subjective well-being in Asia: Psychological, social, and cultural perspectives (pp. 105-121). Seoul, Korea: Kyoyook-Kwahak-Sa.

Triandis, H.C. (1989). The self and social behavior in differing cultural contexts. Psychological Review, 96, 506-520.

Triandis, H.C. (1995). Individualism and collectivism. Boulder: Westview Press. Turner, J.C., Hogg, M., Oakes, P., Reicher, S., \& Wetherell, M. (1987). Rediscovering the social group: A self-categorization theory. Oxford: Basil Blackwell.

Wagar, B.M. \& Cohen, D. (2003). Culture, memory, and the self: An analysis of the personal and collective self in long-term memory. Journal of Experimental Social Psychology, 39, 468-475.

Yuki, M. (2003). Intergroup comparison versus intragroup relationships: A cross-cultural examination of social identity theory in North American and East 
Asian cultural contexts. Social Psychology Quarterly, 66, 166-183.

Yuki, M., Maddux, W.W., Brewer, M.B., \& Takemura, K. (2005). Cross-cultural differences in relationship- and group-based trust. Personality and Social Psychology Bulletin, 31, 48-62. 


\section{Endnotes}

${ }^{1}$ Based on the conceptualization of intragroup relationship orientation by Yuki (2003), we included two subtypes of intragroup relationship information: six items about each in-group member's cooperativeness and six about the relationships between in-group members (i.e. which member likes/dislikes which member). Because the recognition rates of these two subtypes strongly correlated with each other in both cultures $(r=0.61$ and $0.54, p<0.001$ for the Japanese and US samples, respectively), we combined these subtypes into a single measure of intragroup relationship orientation.

${ }^{2}$ We did not include participants' demographic factors, such as sex, age, and socioeconomic status, in the current analyses for the following reasons. First, sex ratios did not differ significantly between cultures, as indicated by $\chi^{2}(1)=1.71, p=0.192$. In addition, the interaction effect of culture and information type remained nearly significant when sex was included as an independent variable $[F(1,109)=3.53, p=$ 0.063], and the effect size of this interaction effect $\left(\eta_{\mathrm{p}}{ }^{2}=0.031\right)$ was approximately the same as in the ANOVA when sex was not included as an independent variable $\left(\eta_{\mathrm{p}}{ }^{2}=\right.$ 0.035). Thus, we collapsed across sex in the current analyses. Second, although the average age for the US sample was higher than that of the Japanese sample $[t(55.997)=$ 4.48, $p<0.001]$, there was no significant correlation between age and recognition rates 
within each culture, as indicated by $r=0.13, p=0.253$ and $r=0.13, p=0.272$ for intragroup relationship information and intergroup comparison information, respectively, in Japan, and $r=0.29, p=0.082$ and $r=0.15, p=0.373$ for intragroup relationship information and intergroup comparison information, respectively, in the USA. Likewise, although participants' self-reported socioeconomic status of the household in which they grew up in was higher for the US sample than for the Japanese sample, as indicated by $t(110)=2.83, p=0.006$, it did not correlate with the memory performances $(r<0.12, p$ $>0.313)$.

${ }^{3}$ A 2 (culture) x 2 (information type) x 3 (scenario), mixed-model ANOVA on the recognition rate revealed that the interaction effect between culture and information type was not moderated by scenario $\left[F(2,222)=0.80, p=0.436, \eta_{\mathrm{p}}{ }^{2}=0.007\right]$. We therefore averaged across scenarios in our results. 
Culture and Groups 20

\section{Figure Captions}

Figure 1. Means of the recognition rate for intragroup relationship information and intergroup comparison information by culture. 


\section{Figure 1}

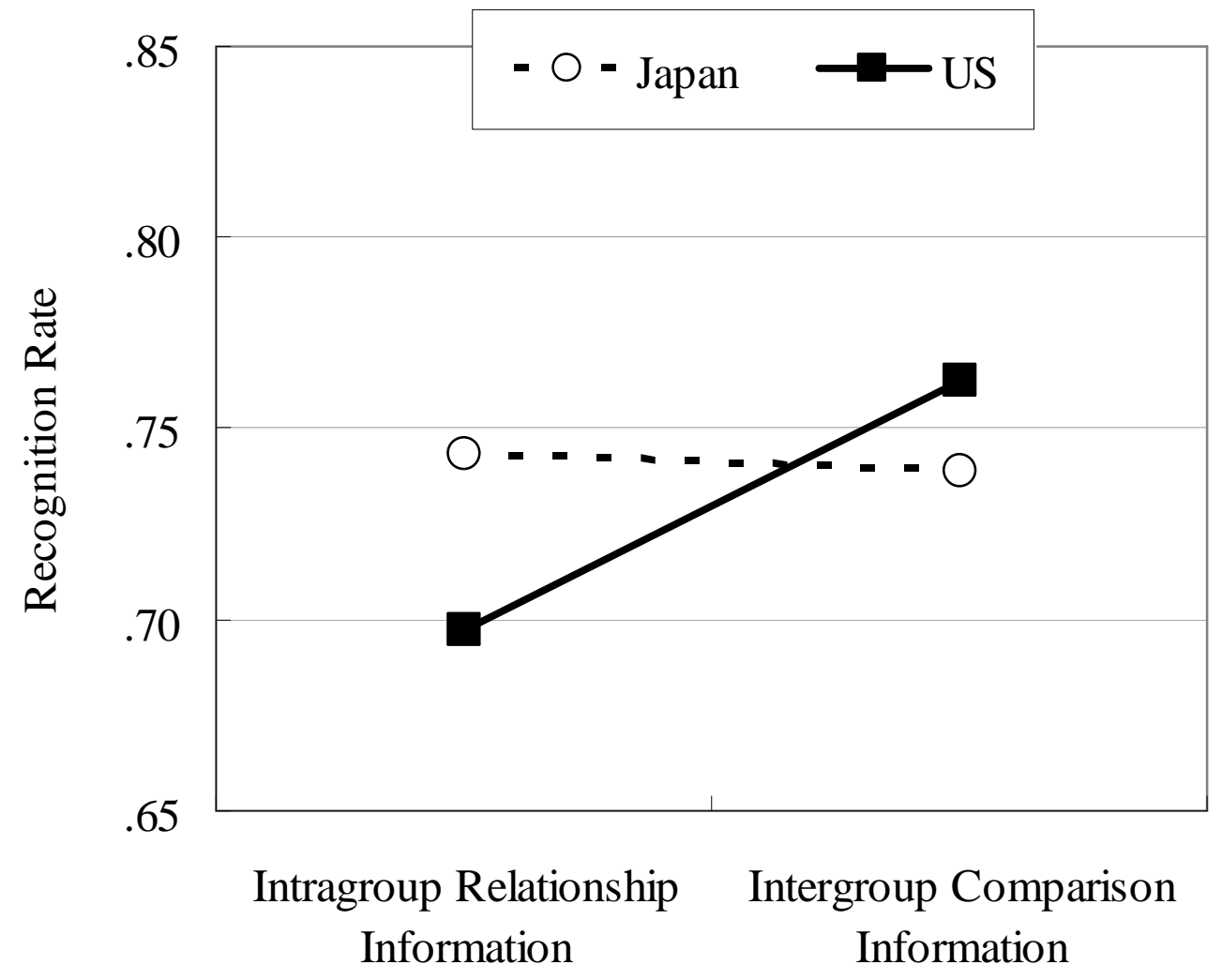

